\title{
Análise de eficiência, aplicação e custo de três impermeabilizantes comerciais
}

\author{
Ana Paula Brandão Capraro 1,2 (b) orcid.org/0000-0001-6270-6568 \\ Renata dos Santos Kmick 3,4 (i) orcid.org/0000-0002-8153-9555 \\ Micheli Gislon Gazolla 3,4 (i) orcid.org/0000-0001-9753-0291 \\ Renato Moura da Silva Junior 3,4 (D) orcid.org/0000-0003-3791-6066 \\ Claiton Cremonez ${ }^{3,4}$ (D) orcid.org/0000-0001-5827-5486 \\ ${ }^{1}$ Universidade Federal do Paraná, Curitiba, Brasil \\ 2 Programa de Pós-Graduação em Engenharia da Construção Civil \\ ${ }^{3}$ Centro Universitário Araucária, Araucária, Brasil \\ ${ }^{4}$ Graduação em Engenharia Civil \\ E-mail do autor principal: Ana Paula Brandão Capraro anapcapraro@gmail.com
}

\section{Resumo}

Dentro da área de estudo da durabilidade das edificações a atividade de impermeabilização merece destaque, por ser uma das responsáveis em proporcionar a integridade e a segurança das estruturas ao longo de suas vidas úteis. Encontra-se no mercado uma grande variedade de produtos destinados a atividade, sendo eles com diferentes composições, princípios de funcionamento e modos de aplicação. Diante do exposto, o objetivo desse estudo foi analisar comparativamente três sistemas de impermeabilização, um a base de emulsão asfáltica, outro de resina acrílica e um terceiro de resina termoplástica, sendo as variáveis de análise: o custo, a produtividade e a eficiência na utilização de ambos em lajes de cobertura. O estudo da eficiência foi realizado por meio de ensaios experimentais de absorção por imersão, absorção por capilaridade e teste de estanqueidade. Para a análise do custo foi considerado o valor unitário médio de mercado de cada produto. Os resultados indicam desempenhos semelhantes entre três produtos estudados, sendo a taxa de absorção por imersão média de $0,47 \%$. O ensaio de estanqueidade, realizado por 72 horas, não indicou falha de nenhum sistema, sendo todos considerados estanques. Contudo, realizando a análise das variáveis de forma conjunta nota-se um melhor custo benefício para o uso da resina acrílica, pois esta foi a que obteve o menor custo por $\mathrm{m}^{2}, \mathrm{R} \$ 67,68$.

Palavras-Chave: Impermeabilização; Durabilidade das Edificações; Vida útil; Eficiência; Custo Benefício.

\section{Abstract}

Considering the area of the durability of buildings, the waterproofing activity deserves to be highlighted, as it is one of those responsible for providing the integrity and safety of structures throughout their useful lives. There is a wide variety of products available for the activity, with different compositions, operating principles and modes of application. The objective of this study was to comparatively analyze three waterproofing systems, one based on asphalt emulsion, another one made of acrylic resin and a third one made of thermoplastic resin, with the analysis variables being the cost, productivity and efficiency in the use of both on roof slabs. The efficiency study was carried out by means of experimental tests of absorption by immersion, absorption by capillarity and leakproofness test. For the cost analysis, the average market value of each product was considered. The results indicate similar performances among the three products studied, with an average 
immersion absorption rate of $0.47 \%$. The leakproofness test, carried out for 72 hours, did not indicate failure of any system, being all considered leakproof. However, carrying out the analysis of the variables together, we note a better cost benefit for the use of acrylic resin, as this was the one that obtained the lowest cost per $\mathrm{m}^{2}, R \$ 67.68$.

Key-words: Waterproofing; Durability of the buildings; Useful life; Efficiency; Cost-effectiveness.

\section{Introdução}

A umidade pode ser considerada como um grande obstáculo na construção civil, pois, conforme Perez [1], sua presença representa um dos problemas mais difíceis de serem corrigidos nas edificações. Para Souza [2], os problemas decorrentes da presença de umidade geram grandes problemas nas edificações, tanto na sua funcionalidade, acarretando em prejuízos financeiros, como danos aos bens materiais, a saúde e conforto do usuário.

Por falta de proteção, a infiltração de água é responsável por abreviar a vida útil das construções [3, 4 e 5]. Segundo Verçoza [6], a umidade, além de ser um dos mecanismos degradantes que ocorre na edificação, é também um meio de surgimento de outras manifestações patológicas, como o aparecimento de eflorescências, ferrugens, mofo, bolores, perda de pinturas e revestimentos e até a causa de acidentes estruturais. Sendo assim, a impermeabilização assume um papel importante na durabilidade das edificações.

Grande parte das falhas de uma impermeabilização pode ser atribuída a sua inexistência ou a falta de importância que é destinada na concepção de seu projeto. O projeto de impermeabilização tem como objetivo analisar, elaborar, detalhar e descrever o melhor método e material a ser adotado, a fim de obter um satisfatório comportamento da impermeabilização e compatibilização com demais projetos da edificação [7 e 8].

De acordo com Cichinelli (2007) [9], além da falta do projeto de impermeabilização, a má execução também pode ser responsável por falhas nesse sistema, como aplicação equivocada da emenda no caso das mantas e da espessura no caso de membranas.

Há inúmeros materiais, marcas e tipos de produtos na construção civil para impermeabilização, assim sendo, a escolha da solução deve ser determinada pelo elemento construtivo, bem como suas funções e desempenho que a requeiram [10].

$\mathrm{Na}$ engenharia, a viabilidade econômica tem um grande poder de decisão nas escolhas de materiais. Os impermeabilizantes, por se tratarem de materiais industrializados, de modo geral possuem um custo elevado. Porém, antes de se buscar produtos com custos mais baixos, deve-se considerar a questão de qualidade e da vida útil do material escolhido [11].

Por haver no mercado uma grande variedade de produtos destinados a atividade de impermeabilização, com diferentes composições, preços, princípios de funcionamento e modos de aplicação, o objetivo desse trabalho foi realizar uma análise comparativa de eficiência, através de ensaios experimentais, juntamente com análise de custo e produtividade, de três impermeabilizantes moldados in loco, com finalidade de analisar o custo-benefício de cada produto na utilização em coberturas não transitáveis.

\section{Materiais e métodos}

O presente estudo contou então com a realização de um programa experimental para a análise de desempenho dos impermeabilizantes.

\section{$2.1 \quad$ Materiais}

Os produtos impermeabilizantes empregados na pesquisa foram selecionados de acordo com guia de aplicação da norma de desempenho para impermeabilização do IBI - Instituto Brasileiro de Impermeabilização [12]. O critério de escolha foi a vida útil de projeto (VUP) de cada produto, sendo uma emulsão asfáltica, com VUP de 8 anos, uma membrana a base resina acrílica, com VUP de 16 anos, 
e por fim uma membrana de resina termoplástica, com VUP de 25 a 30 anos.

A emulsão asfáltica, normatizada pela NBR 9685 [13], possui como componente principal o asfalto (40 - 70\% de concentração) e densidade de 0,95 a 1,05 $\mathrm{Kg} / \mathrm{L}$. A membrana acrílica, normatizada pela NBR 13321 [14], é composta por água, cargas minerais, emulsão acrílica, pigmento, estabilizantes, antiespumante e biocida, sua densidade é de aproximadamente $1,2 \mathrm{~kg} / \mathrm{L}$. Por fim, a resina termoplástica, NBR 15885 [15], é composta por polímeros acrílicos e cimento Portland ( $25-50 \%$ de concentração) e sua densidade é de $1,60 \mathrm{~kg} / \mathrm{L}$.

Os concretos a serem impermeabilizados pelos produtos listados anteriormente foram confeccionados com cimento Portland CPV - ARI, traço base $1: 1: 6$, com relação água cimento de 0,495 , resultando em um material de resistência de $35 \mathrm{MPa}$.

O cimento empregado possui massa específica de $3,13 \mathrm{~g} / \mathrm{cm}^{3}$ e foi escolhido por ser a opção comercial com mais rápida hidratação, permitindo que os ensaios aos 28 dias representassem concretos com estágios de hidratação avançados.

O agregado miúdo empregado possui dimensão máxima de $2,4 \mathrm{~mm}$ e massa específica de $2,62 \mathrm{~g} / \mathrm{cm}^{3}$ e o agregado graúdo, brita 1 , possui massa específica de $2,65 \mathrm{~g} / \mathrm{cm}^{3}$.

\subsection{Análise de desempenho e eficiência - Ensaios Experimentais}

Para análise de desempenho e eficiência dos produtos foram moldados corpos de provas cilíndricos, com dimensões de $0,10 \times 0,20 \mathrm{~m}$ e lajes, com dimensões de $0,60 \times 0,60 \times 0,07 \mathrm{~m}$ (dimensões adotadas com base no estudo de Vasconcelos e Bauer (2018) [16]). Parte das amostras receberam os produtos impermeabilizantes estudados e outra parte foi mantida sem produto, a fim de representar a série referência.

Após a cura de 28 dias do concreto foi realizada a aplicação dos produtos (EA - emulsão asfáltica; MA membrana acrílica; RT - resina termoplástica), conforme as orientações das fichas técnicas dos fabricantes, conforme Tabela 1.
Tabela 1: Critérios para aplicação dos produtos.

\begin{tabular}{c|c|c|c|c}
\hline Produto & Requisito & $\begin{array}{c}\text { Intervalo } \\
\text { (hora) }\end{array}$ & $\begin{array}{c}\text { Secagem } \\
\text { (dias) }\end{array}$ & \\
\hline EA & $\begin{array}{c}2 \text { a } 3 \\
\text { demãos }\end{array}$ & 12 & 5 & \\
\hline MA & $\begin{array}{c}3 \text { à } 4 \\
\text { demãos }\end{array}$ & 6 & 1 & \\
\hline RT & $\begin{array}{c}\text { Espessura } \\
\text { de 2mm a } \\
4 \mathrm{~mm}\end{array}$ & 6 & 7 & \\
\hline
\end{tabular}

Para análise de desempenho os ensaios realizados foram: teste de estanqueidade, absorção por imersão e absorção por capilaridade.

Para o teste de estanqueidade foram empregadas 4 lajes, as quais foram submetidas a uma lâmina de água de $0,03 \mathrm{~m}$ por 72 horas, através de um recipiente transparente e vedado, conforme recomendação da Anexo C NBR 15575-3 [17], Figura 1.

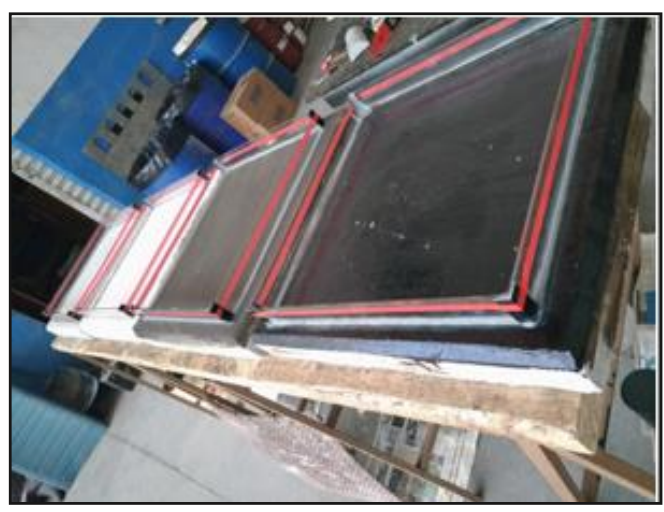

Figura 1: Teste de estanqueidade realizado nas quatro lajes estudadas.

Para o ensaio de absorção por imersão (Figura 2) foram utilizados 20 corpos de prova, sendo estes ensaiados de acordo com a NBR 9778 [18], sendo 5 com aplicação de cada produto e 5 para a série referência, sem aplicação. Após a aplicação e secagem dos produtos, os corpos de prova foram levados a estufa por 72 horas, a $40^{\circ} \mathrm{C}$ e, após a secagem, foram registradas a massa da amostra seca e das amostras que foram submersas, sob temperatura ambiente pelos períodos de 24 horas, 48 horas e 72 horas. 


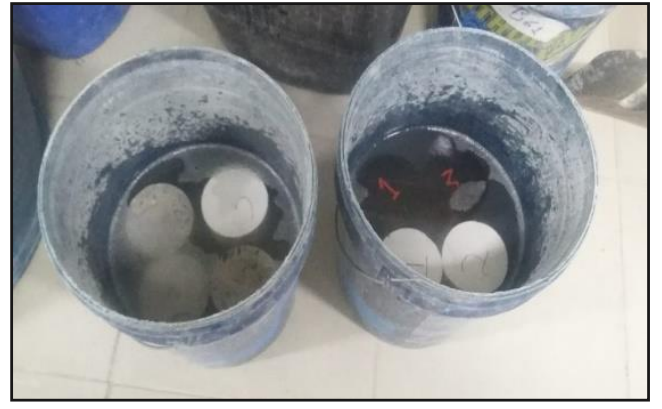

Figura 2: Ensaio de absorção de água por imersão.

Simultaneamente foi realizado o ensaio de absorção por capilaridade, conforme NBR 9779 [19]. Foram utilizados novamente 20 corpos de prova, sendo 5 impermeabilizados pela metade (parte em contato com a água), com cada impermeabilizante, (Figura 3), e 5 como referência, sem aplicação de produto.

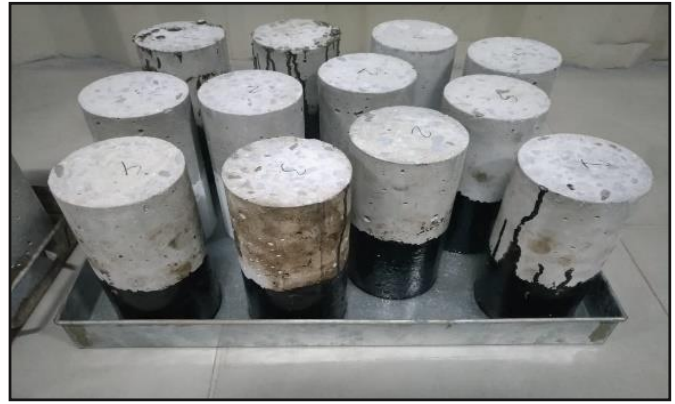

Figura 3: Ensaio de absorção por capilaridade.

Após o ensaio, os corpos de prova foram rompidos por compressão diametral, conforme Figura 4, para avaliação da percolação de água no interior das amostras.

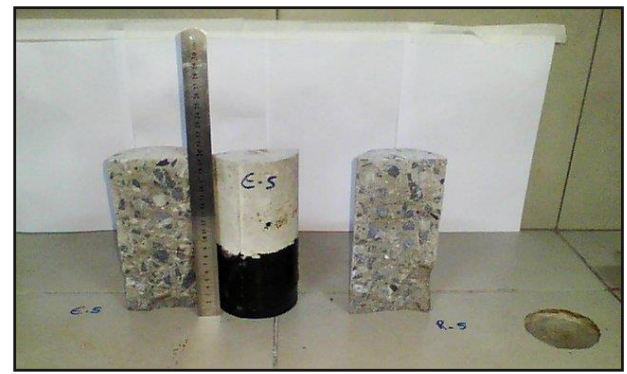

Figura 4: Ensaio de absorção por capilaridade rompimento à compressão diametral.

\subsection{Análise de aplicação e custo}

Para análise comparativa do custo inicial médio dos três produtos analisados, o custo $/ \mathrm{m}^{2}$ impermeabilizado foi obtido a partir do custo unitário das atividades, com base nos dados de produtividade de mão de obra da TCPO 2018 [20] e com preços e encargos sociais da SINAPI, aplicados ao estado do Paraná, com referência a agosto de 2019 [21]. Para verificação da produtividade foi adotado o cronograma para a realização da impermeabilização em $1 \mathrm{~m}^{2}$ de cobertura, considerando as etapas mínimas de aplicação, de acordo com os respectivos fabricantes, e dias úteis trabalhados.

\section{Resultados e discussões}

Após a realização da coleta de dados dos ensaios experimentais e da análise de aplicação e custos de cada produto, foi demonstrado individualmente $\mathrm{o}$ resultado obtido em cada ensaio.

\subsection{Teste de estanqueidade}

Após a submissão das lajes ao teste de estanqueidade as mesmas foram observadas por 72 horas. Ao final do ensaio não foi constatado o aparecimento de bolhas ou infiltração na parte inferior das amostras, e também não foi observado $p$ rebaixamento do nível da água na referência de $0,03 \mathrm{~m}$, nas condições e no período estudado. Sendo assim, todas as lajes foram consideradas estanques, conforme Figura 5. 

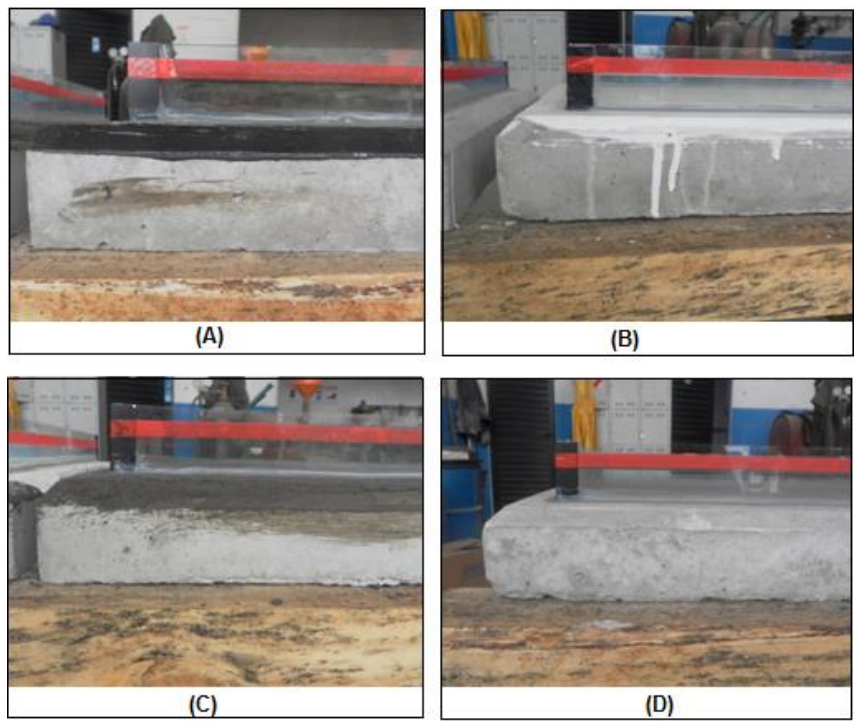

Figura 5: Resultado teste de estanqueidade após 72 horas. A - Laje com emulsão asfáltica; B - Laje com membrana acrílica; C - Laje com resina termoplástica; D - Laje referência.

Oliveira, Fraga e Barboza (2013) [10] indicam em um estudo comparativo entre emulsão acrílica e cimentícia a estanqueidade, após 72 horas de ensaio, para os dois materiais, de forma semelhante ao obtido neste estudo.

Desta forma, para o ensaio proposto neste item, não foi possível a identificação de um produto que demonstrasse um desempenho superior aos demais, visto que até mesmo a série referência mostrou-se estanque.

\subsection{Ensaio de absorção por imersão}

A Figura 6 apresenta os resultados coletados para a taxa de absorção por imersão. A taxa média inicial de absorção nos corpos de prova impermeabilizados foi de $0,32 \%$ e dos corpos de prova referência a taxa média foi $5,18 \%$. Após o período de 72 horas, a taxa média de absorção foi de $0,47 \%$, para os corpos de prova impermeabilizados e de $5,30 \%$ para a série referência.

Analisando os resultados obtidos para as séries impermeabilizadas notou-se um comportamento semelhante entre elas, e satisfatório se comparado à série referência. Pelo desvio padrão obtido as séries emulsão asfáltica e resina termoplástica puderam ser consideradas estatisticamente equivalentes pelo teste de Tukey nas leituras realizadas. Na idade final avaliada, 72 horas de ensaio, a membrana acrílica apresentou o menor valor, validado estatisticamente, entre todas as séries avaliadas, indicando seu melhor desempenho durante este ensaio.

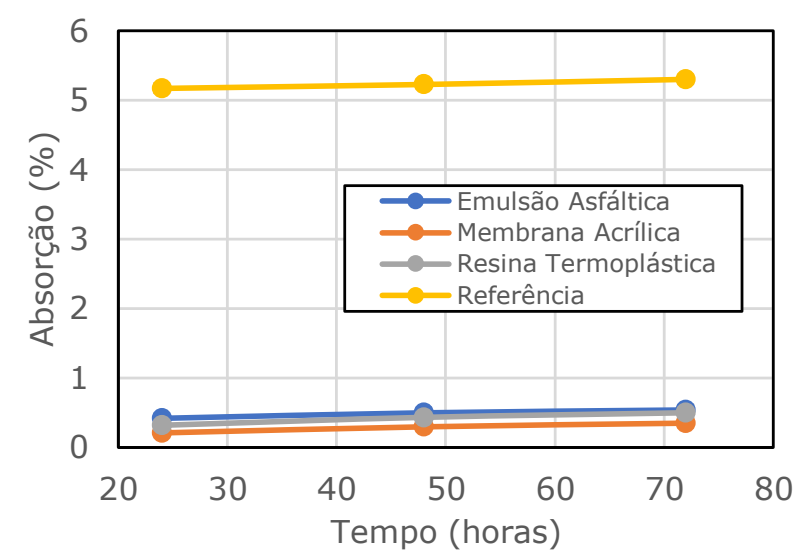

Figura 6: Absorção de água por imersão.

Relacionando os valores obtidos por Barasuol [22], o qual realizou o ensaio de imersão em concretos sob cura em baixas temperaturas, com resistência $25 \mathrm{MPa}$ e uso de cimento CP- IV com brita 0 e 1 , afim de reduzir os índices de vazios, o mesmo obteve uma taxa de absorção por imersão de 5,97\%, sendo assim observa-se que comportamento da série referência foi coerente ao relatado pela literatura.

Colombo e Piva (2017) [23], realizaram um estudo comparativo semelhante, entre uma emulsão asfáltica e uma resina acrílica. Segundo os autores, a resina apresentou menor absorção $(1,3 \%)$ quando comparada a emulsão $(1,7 \%)$, confirmando o resultado obtido neste estudo. Contudo, nota-se que a absorção observada nos dois materiais foi superior a apresentada neste estudo, podendo ser justificada pela diferença do substrato (traço do concreto) e do produto ensaiado (fabricante).

\subsection{Ensaio de absorção por capilaridade}

O comportamento dos corpos de provas com produtos impermeabilizantes após o ensaio de absorção por capilaridade, nos períodos de 03 e 06 horas, pode-se considerar similar, pois a média de taxa de absorção entre esses períodos foi de $0,68 \%$. Porém, após o período de 24 horas, os corpos de prova da série resina termoplástica apresentaram uma taxa de absorção de $0,15 \%$, contra a taxa de

DOI: $10.25286 /$ repa.v6i1.1426 
absorção da emulsão asfáltica de $1,66 \%$ e da membrana acrílica de $0,97 \%$. No período de 72 horas, a série referência teve uma absorção de $7,92 \%$ a mais em relação a resina termoplástica, que teve o melhor comportamento. A emulsão asfáltica e membrana acrílica se mantiveram com equivalente estatisticamente, considerando a maior variabilidade de desvio padrão entre eles, conforme Figura 7.

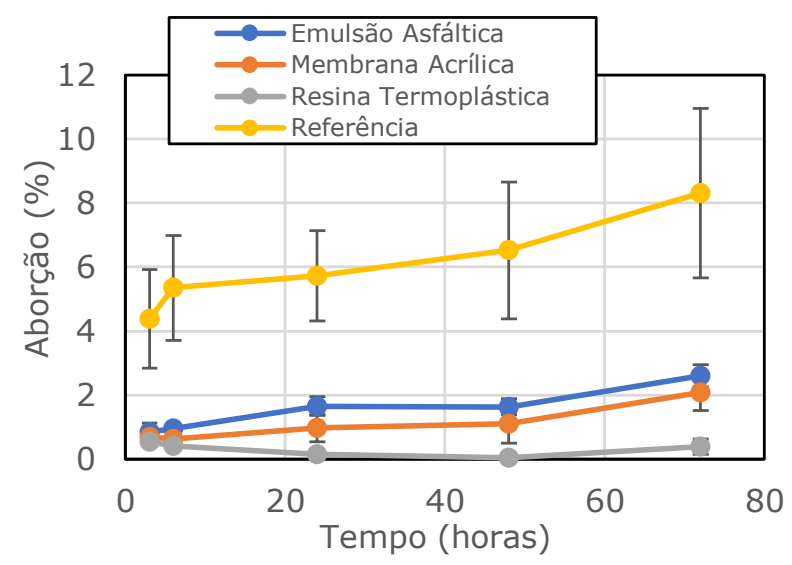

Figura 7: Absorção de água por capilaridade.

O comportamento dos corpos de prova, no ensaio apresentado no item anterior foi linear e proporcional, diferente do comportamento da absorção por capilaridade, mostrando que a umidade por ascensão capilar foi mais presente que a pressão exercida nos corpos submersos, exceto na resina termoplástica. Esse produto, conforme Pezzolo [24], é indicado para impermeabilização em rodapés de paredes de drywall, e os resultados confirmam um bom desempenho para essa finalidade.

A análise da ascensão capilar nos corpos de prova rompidos por compressão diametral não foi possível nas séries impermeabilizadas, isto porque a absorção observada nestes casos foi muito baixa. Já para a série referência foi observada uma altura média de percolação de $5,3 \mathrm{~cm}$, como indicado na Figura 8 .

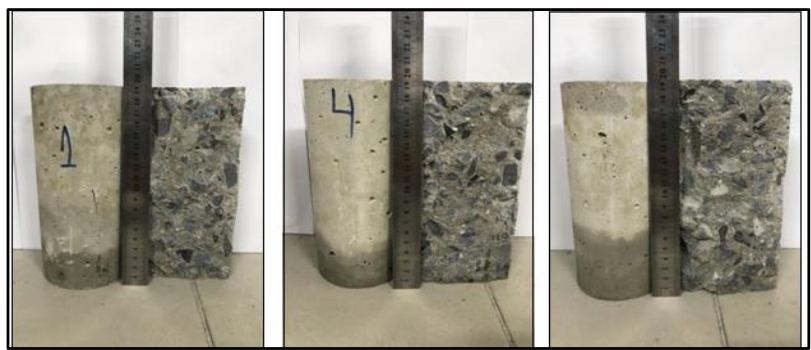

Figura 8: Corpos de prova da série referência na análise de ascensão capilar após o ensaio de compressão diametral.

\subsection{Aplicação e custo}

Para a análise da produtividade foram analisados os dados dispostos na Tabela 2, com a comparação de consumo de cada produto, indicado pela ficha técnica para pressões positivas, e pelo consumo médio obtido na aplicação dos produtos para os ensaios.

Tabela 2: Consumo médio dos produtos impermeabilizantes.

\begin{tabular}{c|c|c}
\hline Produto & $\begin{array}{c}\text { Consumo ficha } \\
\text { técnica }\end{array}$ & $\begin{array}{c}\text { Consumo } \\
\text { real }\end{array}$ \\
\hline EA & 4,0 a $5,0 \mathrm{~kg} / \mathrm{m}^{2}$ & $4,23 \mathrm{~kg} / \mathrm{m}^{2}$ \\
\hline MA & $2,0 \mathrm{~kg} / \mathrm{m}^{2}$ & $2,54 \mathrm{~kg} / \mathrm{m}^{2}$ \\
\hline RT & $4,0 \mathrm{~kg} / \mathrm{m}^{2}$ & $6,23 \mathrm{~kg} / \mathrm{m}^{2}$ \\
\hline
\end{tabular}

Devido a aplicação ser realizada em corpos de prova cilíndricos e os materiais impermeabilizantes terem a finalidade para aplicação em locais planos, como em lajes e coberturas, houveram dificuldades. $\mathrm{Na}$ aplicação da resina termoplástica não foi possível o atingimento do consumo conforme solicitado pela ficha técnica, contudo, visualmente, notou-se um bom desempenho no cobrimento dos microporos da superfície das amostras. O mesmo não ocorreu na aplicação da emulsão asfáltica, na qual observou-se, nas primeiras demãos, que nos locais onde havia a necessidade de tamponamento dos microporos, surgiram bolhas de ar, sendo uma possível causa a consistência do material, conforme Figura 9. 


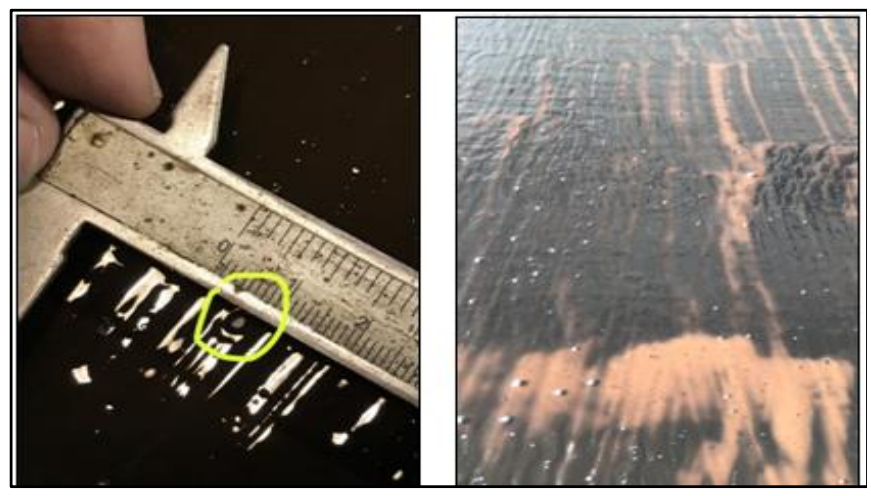

Figura 9: Aplicação da emulsão asfáltica na laje.

Nas etapas de preparo, o produto que mostrou ter maior facilidade de aplicação foi a membrana acrílica, sendo um material líquido de fácil aderência, não havendo perda de material.

Na Tabela 3 estão dispostos os valores médios de mercado de produtos similares aos referenciados na pesquisa, para análise de custo unitário e produtividade.

Tabela 3: Preço médio dos impermeabilizantes.

\begin{tabular}{c|c}
\hline Produto & $\begin{array}{c}\text { Preço médio de } \\
\text { mercado }\end{array}$ \\
\hline EA & $\mathrm{R} \$ 8,72 \mathrm{~kg}$ \\
\hline $\mathrm{MA}$ & $\mathrm{R} \$ 12,42 \mathrm{~kg}$ \\
\hline $\mathrm{RT}$ & $\mathrm{R} \$ 6,80 \mathrm{~kg}$ \\
\hline
\end{tabular}

A partir desses dados, pode-se elaborar a composição de preço unitário (CPU) de aplicação por $\mathrm{m}^{2}$ de cada produto, sendo a Tabela 4 da emulsão asfáltica.

Tabela 4: CPU impermeabilização com emulsão asfáltica.

\begin{tabular}{l|c|c|c|c}
\hline \multicolumn{1}{c|}{ Descrição } & Ud & Coef & Preço & Total \\
\hline $\begin{array}{l}\text { IMPERMEABILIZAÇÃO a } \\
\text { base de emulsão asfáltica }\end{array}$ & $\mathrm{M}^{2}$ & - & & $\mathrm{R} \$ 105,00$ \\
\hline $\begin{array}{l}\text { Ajudante de aplicador de } \\
\text { impermeabilização }\end{array}$ & $\mathrm{H}$ & 0,50 & 19,86 & $\mathrm{R} \$ 9,93$ \\
$\begin{array}{l}\text { Aplicador } \\
\text { impermeabilização de }\end{array}$ & $\mathrm{H}$ & 0,50 & 21,86 & $\mathrm{R} \$ 10,93$ \\
$\begin{array}{l}\text { Proteção mecânica com } \\
\text { argamassa de cimento e } \\
\text { areia }\end{array}$ & $\mathrm{M}^{2}$ & 1,00 & 24,11 & $\mathrm{R} \$ 24,11$ \\
\hline
\end{tabular}

\begin{tabular}{l|c|c|c|c}
\hline Emulsão adesiva & $\mathrm{KG}$ & 0,40 & 7,94 & $\mathrm{R} \$ 3,18$ \\
Emulsão asfáltica & $\mathrm{KG}$ & 4,00 & 8,72 & $\mathrm{R} \$ 34,88$ \\
Véu de poliéster & $\mathrm{M}^{2}$ & 1,10 & 19,98 & $\mathrm{R} \$ 21,98$ \\
& & & & \\
\hline
\end{tabular}

Fonte: Adaptado de [20] e [21].

Os produtos membrana acrílica e resina termoplástica, em suas fichas técnicas não exigem a camada de proteção mecânica. Na Tabela 5 e 6 estão apresentadas as CPU'S de aplicação da membrana acrílica e resina termoplástica, respectivamente.

Tabela 5: CPU impermeabilização com membrana acrílica.

\begin{tabular}{l|c|c|c|c}
\hline \multicolumn{1}{c|}{ Descrição } & Ud & Coef & Preço & Total \\
\hline $\begin{array}{l}\text { IMPERMEABILIZAÇÄO à } \\
\text { base de resina acrílica }\end{array}$ & $\mathrm{M}^{2}$ & - & & $\mathrm{R} \$ 67,68$ \\
\hline $\begin{array}{l}\text { Ajudante de aplicador de } \\
\text { impermeabilização }\end{array}$ & $\mathrm{H}$ & 0,50 & 19,86 & $\mathrm{R} \$ 9,93$ \\
$\begin{array}{l}\text { Aplicador } \\
\text { impermeabilização de }\end{array}$ & $\mathrm{H}$ & 0,50 & 21,86 & $\mathrm{R} \$ 10,93$ \\
$\begin{array}{l}\text { Membrana acrílica } \\
\text { Véu de poliéster }\end{array}$ & $\mathrm{KG}$ & 2,00 & 12,42 & $\mathrm{R} \$ 24,84$ \\
& $\mathrm{M} 2$ & 1,10 & 19,98 & $\mathrm{R} \$ 21,98$ \\
\hline
\end{tabular}

Fonte: Adaptado de [20] e [21].

Tabela 6: CPU impermeabilização com resina termoplástica.

\begin{tabular}{|c|c|c|c|c|}
\hline Descrição & Ud & Coef & Preço & Total \\
\hline $\begin{array}{l}\text { IMPERMEABILIZAÇÄO } \\
\text { com resina } \\
\text { termoplástica }\end{array}$ & $M^{2}$ & - & & $R \$ 70,04$ \\
\hline $\begin{array}{l}\text { Ajudante de aplicador } \\
\text { de impermeabilização }\end{array}$ & $\mathrm{H}$ & 0,50 & 19,86 & $R \$ 9,93$ \\
\hline $\begin{array}{ll}\text { Aplicador } & \text { de } \\
\text { impermeabilização } & \end{array}$ & $\mathrm{H}$ & 0,50 & 21,86 & $R \$ 10,93$ \\
\hline $\begin{array}{l}\text { Membrana de polímero } \\
\text { acrílico com cimento }\end{array}$ & KG & 4,00 & 6,80 & $R \$ 27,20$ \\
\hline Véu de poliéster & $M^{2}$ & 1,10 & 19,98 & $\mathrm{R} \$ 21,98$ \\
\hline
\end{tabular}

Fonte: Adaptado de [20] e [21].

Pode-se analisar que o custo unitário do $\mathrm{kg}$ da membrana acrílica é $54,75 \%$ mais caro que a resina termoplástica. Contudo, devido o consumo da membrana acrílica ser menor, o custo unitário do $\mathrm{m}^{2}$ impermeabilizado, neste caso, fica mais baixo. A emulsão asfáltica em relação ao custo, foi a que apresentou o resultado menos satisfatório, pois DOI: $10.25286 /$ repa.v6i1.1426 
devido a necessidade de camada de regularização e seu consumo, o preço total foi de $\mathrm{R} \$ 105,00 / \mathrm{m}^{2}$ contra $\mathrm{R} \$ 67,68 / \mathrm{m}^{2}$ da resina acrílica, que teve o melhor preço unitário por $\mathrm{m}^{2}$ impermeabilizado.

\section{Conclusões}

Os resultados obtidos neste estudo permitiram apontar as conclusões listadas a seguir:

- Os testes de eficiência (estanqueidade e absorção) apontaram resultados semelhantes entre as séries impermeabilizadas, e somente a membrana acrílica obteve resultado estatisticamente superior no ensaio de absorção por imersão;

- A emulsão asfáltica apresentou perda de material e bolhas ao longo do ensaio, não atendendo requisitos de desempenho da NBR 9685 [13]. Diante desse exposto, seria necessário a avaliação do seu comportamento ao longo do seu uso, a fim de verificar se este desgaste comprometeria seu desempenho;

- Considerando o resultado obtido pelo custo unitário de aplicação, a emulsão asfáltica foi o produto que teve resultado menos satisfatório, sendo o custo médio de aplicação de $\mathrm{R} \$ 105,00$, quando comparada aos demais produtos, com um custo médio de $R \$ 68,00$. Seu custo mais elevado se dá pela necessidade da camada de proteção mecânica, exigida pelo seu fabricante;

- Considerando os resultados obtidos, de eficiência e custo, e considerando a VUP dos sistemas de impermeabilização, destaca-se o comportamento da membrana acrílica e da resina termoplástica;

- Ainda, destaca-se a necessidade de estudos futuros, a fim de verificar o comportamento desses produtos ao longo de sua utilização, confirmando a VUP dos mesmos, e o seu custo, ao longo de seu uso.

\section{Agradecimentos}

Os autores agradecem as agências brasileiras CNPq, Capes e Fundação Araucária pelo apoio financeiro, a Universidade Federal do Paraná (UFPR), ao Programa de Pós-Graduação em Engenharia de Construção Civil (PPGECC), ao Centro Universitário UNIFACEAR e a concreteira NOVAMIX por todo o auxílio dado ao estudo.

\section{Referências}

[1] PEREZ, A R. Umidade nas edificações: Recomendações para a prevenção da penetração de água da chuva pelas fachadas. Tecnologia de Edificações, São Paulo, n. 2, p. 35-42, 1985.

[2] SOUZA, M. F. Patologias ocasionadas pela umidade nas edificações. 2008. 64 f. Monografia (Especialização) - Curso de Especialização em Construção Civil, Departamento de Engenharia de Materiais de Construção, Universidade Federal de Minas Gerais, Belo Horizonte, 2008.

[3] BAUER, E., VASCONCELOS, P.H. C.; GRANATO, J. E. Sistemas de impermeabilização e isolamento térmico. In: ISAIA, G. C. Materiais de construção civil e princípios de ciência e engenharia dos materiais. São Paulo: Ed. IBRACON, 2010, v.2.

[4] CHO, B. H.; NAM, B. H.; SEO, S.; KIM, J.; AM, J.; YOUN, H. Waterproofing performance of waterstop with adhesive bonding used at joints pf underground concrete structures. Construction and Building Materials, V. 221, pp. 491-500, 2019.

[5] MUHAMMAD, N. Z.; KEYVANFAR, A.; MAJID, M. Z. A.; SHAFAGHAT, A.; MIRZA, J. Waterproof performance of concrete: A critical review on implemented approaches. Construction and Building Materials, V. 101, pp. 80-90, 2015.

[6] VERÇOZA, E. J. Patologia das Edificações. Porto Alegre, Editora Sagra, 1991.

[7] ROLIM, F. C.; ALLEM, P. M. Projeto de impermeabilização em piscinas e terraços. Universidade do Extremo Sul Catarinense, 2016.

[8] PINTO CRUZ, J. H. Manifestações patológicas de impermeabilizações com uso de sistema não aderido de mantas asfálticas: avaliação e análise com auxílio de sistema multimídia. Dissertação de Mestrado - URGS. Porto Alegre, 2013. 
[9] CICHINELLI, G. Impermeabilização. 87. Ed. Revista Téchne, São Paulo: Pini, 2007.

[10] OLIVEIRA, M. F. F.; FRAGA, J. B.; BARBOZA, A. C. R. N. Avaliação de desempenho de emulsões acrílicas para membranas impermeabilizantes cimenticiais. $13^{\circ}$ Simpósio Brasileiro de Impermeabilização, IBI, 2013.

[11] RODRIGUÊS, R. M.; SOBRINHO JÚNIOR, A. S.; LIMA, E. E. P. Erros, diagnósticos e soluções de impermeabilizações na construção civil. Inter Sciencia, Paraíba, v. 4, n. 2, p.1-15, 06 out. 2016. [12] MORGADO, J. M. et al. Guia de aplicação da norma de desempenho para impermeabilização. Especificação, aplicação e contratação com foco no atendimento à ABNT 15575/2013. Rio de Janeiro: IBI - Instituto Brasileiro de Impermeabilização, 2018.

[13] ASSOCIAÇÃO BRASILEIRA DE NORMAS TÉCNICAS. NBR 9685: Emulsão Asfáltica para Impermeabilização. Rio de Janeiro, 2005.

[14] ASSOCIAÇÃO BRASILEIRA DE NORMAS TÉCNICAS. NBR 13321: Membrana acrílica para impermeabilização. Rio de Janeiro, 2008.

[15] ASSOCIAÇÃO BRASILEIRA DE NORMAS TÉCNICAS. NBR 15885: Membrana de Polímero Acrílico com ou sem Cimento para Impermeabilização. Rio de Janeiro, 2010.

[16] VASCONCELOS, P. H.; BAUER, E. Estudo comparativo entre ensaios de desempenho e de caracterização de membranas de poliuréia e poliuretano. $15^{\circ}$ Simpósio Brasileiro de Impermeabilização. IBI, 2018.

[17] ASSOCIAÇÃO BRASILEIRA DE NORMAS TÉCNICAS. NBR 15575: Edificações habitacionais - Desempenho. Rio de Janeiro, 2013.

[18] ASSOCIAÇÃO BRASILEIRA DE NORMAS TÉCNICAS. NBR 9778: Argamassa e concreto endurecidos - Determinação da absorção de água, índice de vazios e massa específica. Rio de Janeiro, 2005.

[19] ASSOCIAÇÃO BRASILEIRA DE NORMAS TÉCNICAS. NBR 9779: Argamassa e concreto endurecidos - Determinação da absorção de água por capilaridade. Rio de Janeiro, 2012.

[20] TCPO. Tabela de Composições de Preços para Orçamentos. 15a Edição. São Paulo: PINI, 2018. 920p.

[21] CAIXA ECONÔMICA FEDERAL (CAIXA). Sistema Nacional de Pesquisa de Custos e Índices da Construção Civil - SINAPI. Acesso em: 15 ago. 2019.
[22] BARASUOL, T. D. B Análise da qualidade do concreto curado em baixas temperaturas para traço usual em edificações no município de Campo Mourão. 2014. 55 f. TCC (Graduação) - Curso de Engenharia Civil, Universidade Tecnológica Federal do Paraná, Campo Mourão, 2014.

[23] COLOMBO, E. N.; PIVA, J. H. Avaliação da absorção de água do concreto com impermeabilizantes flexíveis de pintura submetidos a variação térmica. Universidade do Extremo Sul Catarinense, 2017.

[24] PEZZOLO, V. Conheça os tipos de impermeabilizante. Equipe Obra Prima, PINI - 2013. 